\title{
Numerical Investigation of Effect of Nano-Aluminum Addition on NOx and CO Pollutants Emission in Liquid Fuels Combustion
}

\author{
Mina Mehregan and Mohammad Moghiman
}

\begin{abstract}
Liquid fuels play an important role in the production of pollutants in practical combustion systems. Meanwhile evaporation phenomenon is a key parameter in pollutants emission in the combustion of liquid fuels. Recent studies show that nanoparticles have the ability to change the evaporation behavior of the base fluids. Hence these nano scaled particles may affect the production of pollutants in liquid fuels combustion. Therefore, considering the importance of controlling pollutants emission in the combustion of liquid fuels, in this study the influence of adding aluminum nanoparticles on $\mathrm{NO}_{\mathrm{x}}$ and $\mathrm{CO}$ pollutants emission in the combustion of ethanol and $n$-decane liquid fuels has been numerically investigated. The results reveal that mass fraction of pollutants $\mathrm{NO}_{\mathrm{x}}$ and $\mathrm{CO}$ will be decreased by adding nano-aluminum to these fuels. These results confirm that aluminum nanoparticles improve combustion features of ethanol and decane liquid fuels.
\end{abstract}

Index Terms - liquid fuel, nanofluid, nanoparticles, pollutant emission.

\section{INTRODUCTION}

Nanofluids, solutions containing suspended nanoparticles (e.g., metals, oxides, carbides, nitrides, or carbon nanotubes) with typical sizes' range of 10-100 nm, have attracted great interest recently [1]-[7]. Because of their enhanced thermal conductivity, nanofluids can be used in energy-related systems. Murshed et al. [8] provided a comprehensive review of nanofluids applications in transportation, micromechanics and instrumentation, heating, ventilating and air-conditioning (HVAC) and medical fields.

Because of high surface area, nanoscale energetic materials offer high reactivity, shortened ignition delays and fast energy release [9]. Jackson et al. [10] revealed that addition of aluminum nanoparticles could substantially decrease the ignition delay time of slurries of n-dodecane. Tyagi et al. [11] by using a simple hot-plate experiment, found that nano-aluminum significantly enhance the ignition probability of diesel fuel. Beloni et al. [12] studied effects of pure aluminum, mechanically alloyed $\mathrm{Al}_{0.7} \mathrm{Li}_{0.3}$, and nanocomposite $2 \mathrm{~B}+\mathrm{Ti}$ as nano additives on flame length, flame speed and flame temperature of decane-based slurries. Comparing the burning characteristics of fuel droplets with nano- and micron-sized aluminum particles, Gan and Qiao [13] showed that for the same solid loading rate and the same surfactant concentration, the microexplosion behavior of the

Manuscript received July 4, 2013; revised September 2, 2013.

The authors are with the Department of Mechanical Engineering, Ferdowsi University of Mashhad, Mashhad, Iran (e-mail: mi_me200@stu-mail.um.ac.ir,moghiman@um.ac.ir). micron suspension occurred later than the nanosuspension. According to Solero [14], adding $\mathrm{Al}_{2} \mathrm{O}_{3}$ nanoparticles to diesel fuel can improve the combustion features of the spray flame and giving rise to lower $\mathrm{CO}$ emission levels.

These previous investigations have revealed some ignition characteristics of fuels with the addition of nanopartilces. However the effect of nanopartilces on liquid fuels pollutants emission has been rarely studied. The aim of this paper is to numerically determine $\mathrm{NO}_{\mathrm{x}}$ and $\mathrm{CO}$ pollutants emission in combustion of ethanol and n-decane liquid fuels with the addition of $\mathrm{Al}$ nanoparticles.

\section{DESCRIPTION OF PHYSICAL MODEL}

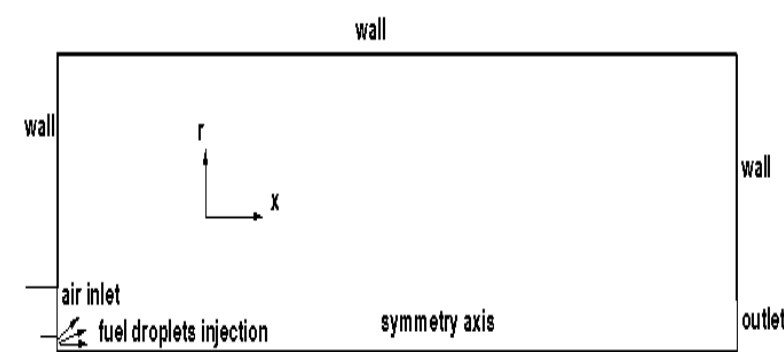

Fig. 1. Employed boundary conditions.

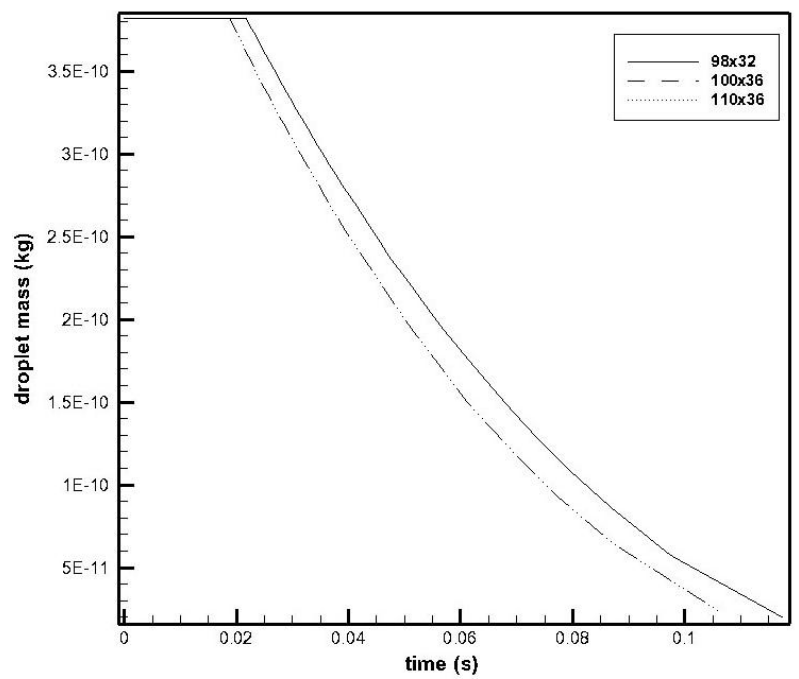

Fig. 2. Droplet mass history for three computational grid sizes.

The flow configuration investigated in this paper is based on a non-premixed swirl-burner. Fuel droplets are injected from the center of a combustion chamber while hot air stream flows around them. The flow has been considered to be two-dimensional and axi-symmetric. Air flow temperature is higher than boiling-point temperature of liquid fuel which causes quick evaporation of droplets. The Re number is 
around 100, the swirl number is set to 0.25 and air inlet axial velocity is $6 \mathrm{~m} / \mathrm{s}$. In Fig. 1, the employed boundary conditions are shown. In order to check grid independency of results, three grid meshes were tested. Fig. 2 presents the temporal evolution of droplet mass obtained by employing these grid meshes. From the figure, it is reasonable to select 100x36 grid nodes as a good compromise between accuracy and computational time.

\section{MATHEMATICAL MODEL}

The governing equations for the gas phase are Reynolds-Averaged Navier-Stokes, energy and species concentration. Turbulence stresses in gas phase equations are modeled by k- $\varepsilon$ method, so two transport equations are also required for turbulent kinetic energy and eddy dissipation rate. The set of governing equations can be conveniently written in a general transport equation form as follows [15]:

$$
\frac{\partial}{\partial t}(\rho \phi)+\operatorname{div}\left(\rho u_{i} \phi\right)=\operatorname{div}\left[\Gamma_{\phi} \operatorname{grad} \phi\right]+S_{\phi}
$$

This generalized transport equation contains transient, convection, diffusion and source terms, respectively where the general variable $\phi$ may represent the mean value of any unknown variable in the aforementioned governing equations. The parameters $\Gamma_{\phi}$ and $S_{\phi}$ represent an effective diffusion coefficient of this general variable and the source term respectively. It has to be noted that in near-wall region, a wall-function approach is used. The gas phase governing equations are solved using SPRINT code [16] which has been validated before against experimental data.

The time-dependent Lagrangian momentum equations for liquid phase are solved numerically to determine velocity and position of droplets [17], [18]. The mass conservation equation for liquid phase is obtained using correction factor introduced by Nikos and Dean [19]. Also by using the correlation reported by Faeth [20] the heat transfer equation is obtained. Clausius-Clapeyron equation of state [21] is employed to predict phase behaviors of system.

The effect of nanopaticles on liquid phase equations is modeled by revising the thermo-physical properties according to following equations [22], [23] for density $(\rho)$, molar mass $(\mathrm{M})$ and heat capacity $\left(\mathrm{C}_{\mathrm{p}}\right)$.

$$
\begin{gathered}
\rho_{n f}=(1-\varphi) \rho+\varphi \rho_{s} \\
M_{n f}=(1-\varphi) M+\varphi M_{s} \\
\left(\rho C_{p}\right)_{n f}=(1-\varphi) \rho C_{p}+\varphi \rho_{s} C_{p, s}
\end{gathered}
$$

where properties with subscript " $s$ " are for nanoparticles whrereas without subscripts are for basefluid. The variable $\varphi$ in above equations represents nanoparticles volume fraction.

Influence of $\mathrm{Al}$ nanoparticles addition on understudied fuels heat of vaporization is obtained using published experimental data of Gan and Qiao [24]. From their results, the difference between the evaporation rate of nanofluid and its base fluid could be obtained and then by employing the well known $\mathrm{D}^{2}$-law, enthalpy of vaporization of nanofluid can be calculated.

Two-step Magnussen model has been used for mathematical modeling of combustion phenomenon and hence for each chemical species, one transport equation must be solved. In addition, to model thermal $\mathrm{NO}_{\mathrm{x}}$ emission in the system, Zeldovich model has been employed.

\section{MOdEL VALIDATION}

In this section the numerical model is validated against reported experimental data of [24]. Note that as suggested by droplet evaporation classical theory [25], the droplet diameter (D) was scaled by the initial droplet diameter $\left(\mathrm{D}_{0}\right)$. As well as it has to be noted that all nanoparticles concentrations are in weight percent.

The temporal evolution of non-dimensionalised droplet square diameter for decane-based fuel obtained from this numerical study is compared with experimental results in Fig. 3. From the figure, it can be observed that present predictions are in good agreement with the experimental data. It has to be noted that there was no available data for pure decane in reported data of [24].

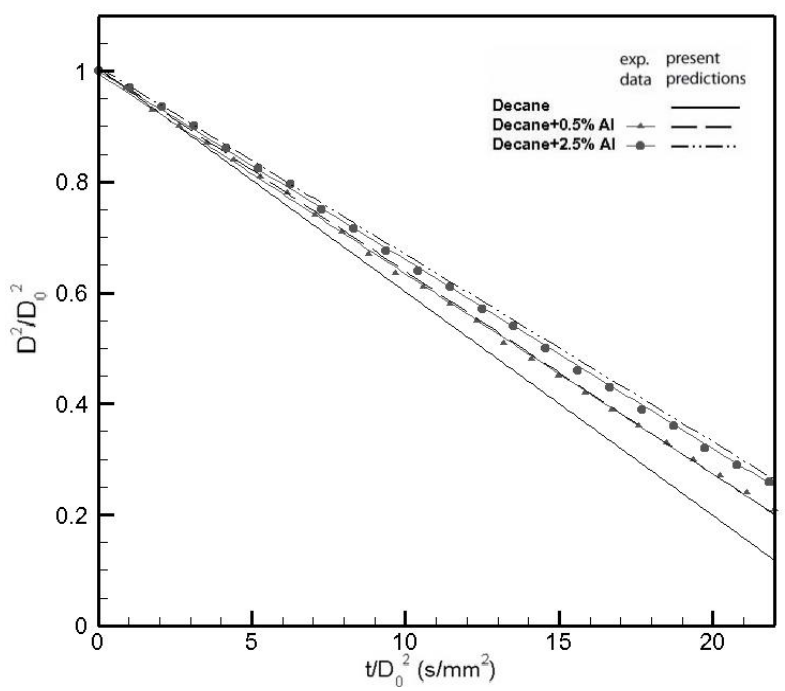

Fig. 3. Droplet size history of decane in contrast with decane+Al.

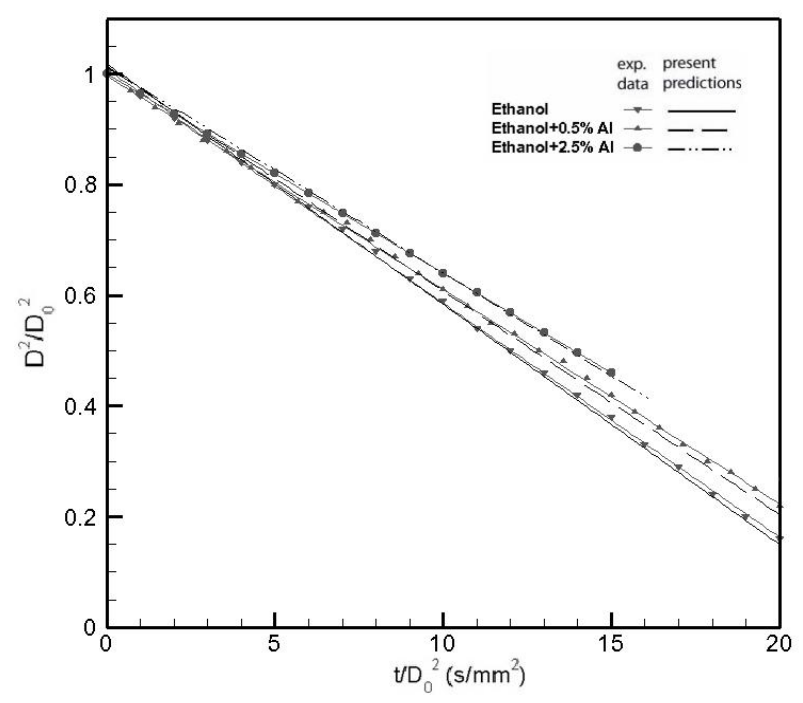

Fig. 4. Droplet size history of ethanol in contrast with ethanol+Al. 
Fig. 4 presents comparison between the temporal evolution of non-dimensionalised droplet square diameter of ethanol-based fuel obtained from this study and experimental results. The figure reveals that present findings are consistent with the experimental data.

\section{RESULTS AND DISCUSSION}

\section{A. Effect of Al Nanopaticles on Pollutants Emission in $N$-Decane Combustion}

Fig. 5 compares pollutant $\mathrm{NO}_{\mathrm{x}}$ emission for decane and decane with the addition of $2.5 \% \mathrm{Al}$. It reveals that nano-aluminum reduces $\mathrm{NO}_{\mathrm{x}}$ emission in decane combustion.

Fig. 6 presents comparison of $\mathrm{CO}$ emission between denace and decane containing $2.5 \% \mathrm{Al}$. It can be observed that adding aluminum nanopartilces leads to a reduction of $\mathrm{CO}$ emission of decane.

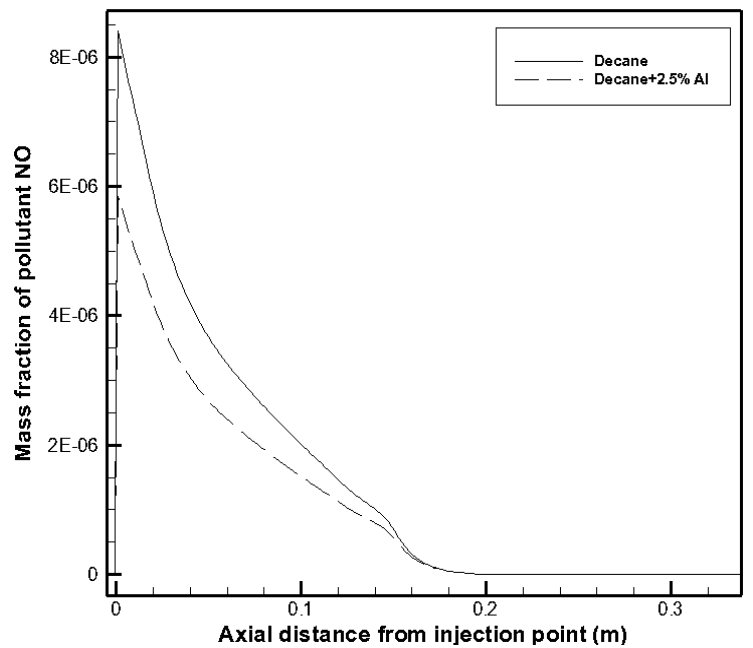

Fig. 5. Centerline distribution of $\mathrm{NO}_{\mathrm{x}}$ mass fraction along the combustor for decane in contrast with decane+2.5\% $\mathrm{Al}$.

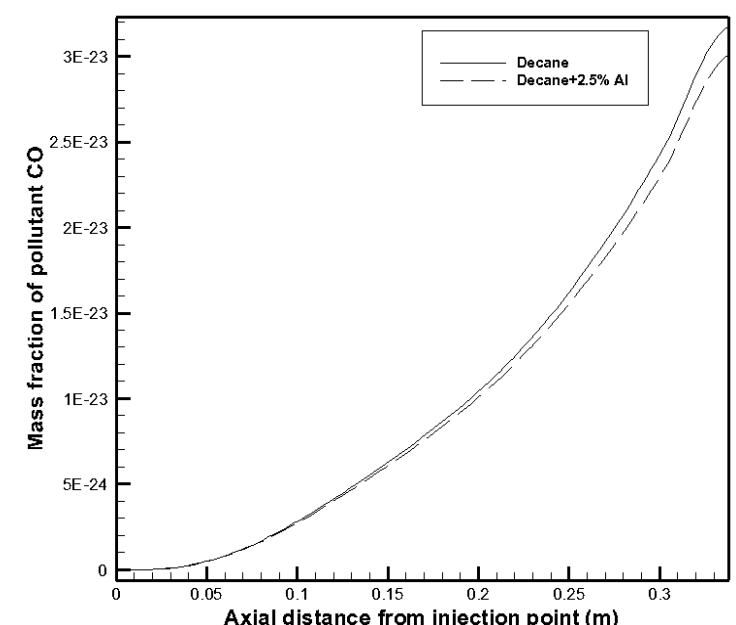

Fig. 6. Centerline distribution of CO mass fraction along the combustor for decane in contrast with decane $+2.5 \% \mathrm{Al}$.

\section{B. Effect of Al Nanopaticles on Pollutants Emission in Ethanol Combustion}

In Fig. 7 pollutant $\mathrm{NO}_{\mathrm{x}}$ emission of ethanol is compared with ethanol containing $2.5 \% \mathrm{Al}$. It reveals that adding aluminum nanopartilces leads to a reduction of $\mathrm{NO}_{\mathrm{x}}$ emission of ethanol.

Fig. 8 demonstrates comparison of $\mathrm{CO}$ emission between ethanol and ethanol with the addition of $2.5 \% \mathrm{Al}$. It can be observed that nano-aluminum reduces $\mathrm{CO}$ emission in ethanol combustion.

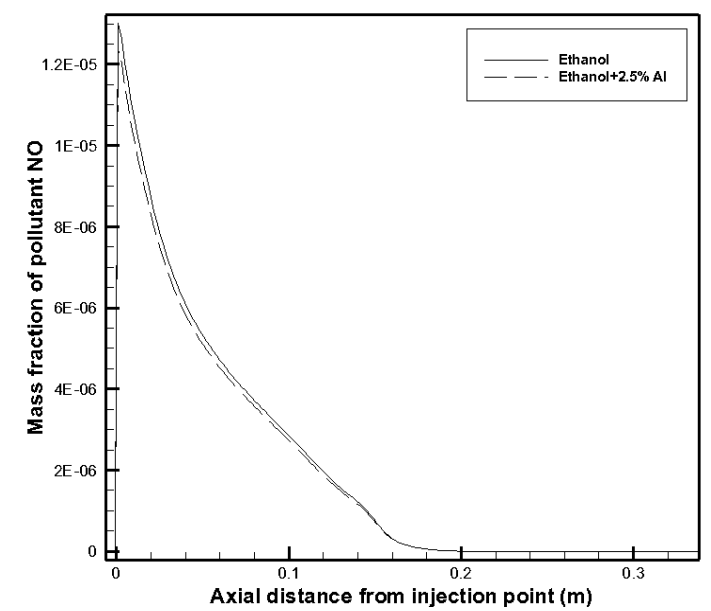

Fig. 7. Centerline distribution of $\mathrm{NO}_{\mathrm{x}}$ mass fraction along the combustor for ethanol in contrast with ethanol $+2.5 \% \mathrm{Al}$.

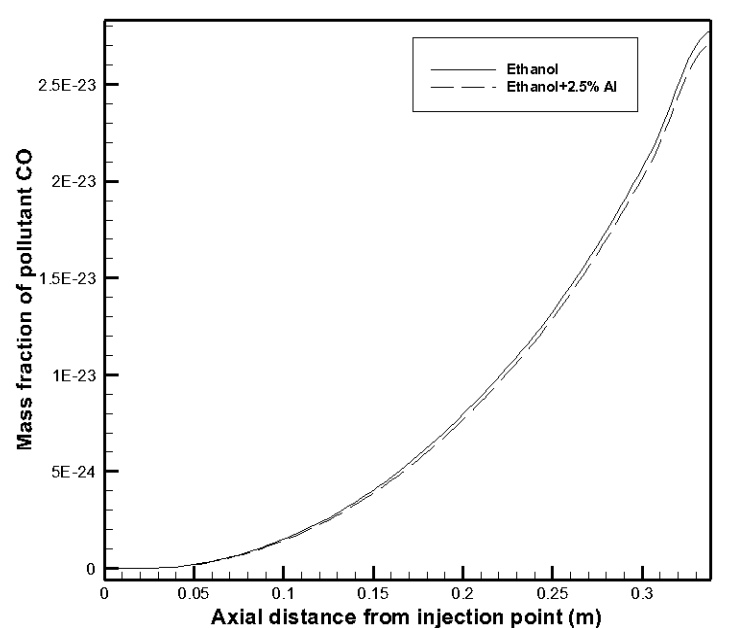

Fig. 8. Centerline distribution of $\mathrm{CO}$ mass fraction along the combustor for ethanol in contrast with ethanol+2.5\% Al.

\section{CONCLUSION}

The pollutants emission of ethanol and n-decane liquid fuels with the addition of aluminum nanoparticles was numerically investigated. The results reveal that, adding nano-aluminum particles to decane and ethanol liquid fuels contributes to lower $\mathrm{NO}_{\mathrm{x}}$ and $\mathrm{CO}$ emission with respect to the pure fuels flame, which confirms improvement of combustion features due to the presence of nanoparticles.

\section{REFERENCES}

[1] S. U. S. Choi and J. A. Eastman, "Enhancing thermal conductivity of fluids with nanoparticles," ASME, pp. 99-105, 1995.

[2] X. Wang, X. Xu, and S. U. S. Choi, "Thermal conductivity of nanoparticle-fluid mixture," Journal of Thermophysics and Heat Transfer, vol. 13, pp. 474-480, 1999.

[3] Y. H. wang, H. S. Park, J. K. Lee, and W. H. Jung, "Thermal conductivity and lubrication characteristics of nanofluids," Current Applied Physics, vol. 6, pp. e67-e71, 2006.

[4] S. K. Das, S. U. Choi, W. Yu, and T. Pradeep, Nanofluids: Science and Technology, New Jersey: John Wiley \& Sons, 2007, Ch. 1, pp. 1-32.

[5] L. Zhang, Y. Jiang, Y. Ding, M. Povey, and D. York, "Investigation into the antibacterial behaviour of suspensions of $\mathrm{ZnO}$ nanoparticles 
(ZnO nanofluids)," Journal of Nanoparticle Research, vol. 9, pp. 479-489, 2007.

[6] S. U. S. Choi, "Nanofluids: from vision to reality through research," Journal of Heat Transfer, vol. 131, pp. 1-9, 2009.

[7] R. H. Chen, T. X. Phuoc, and D. Martello, "Surface tension of evaporating nanofluid droplets," International Journal of Heat and Mass Transfer, vol. 54, pp. 2459-2466, 2011.

[8] S. M. S Murshed, K. C. Leong, and C. Yang, "Thermophysical and electrokinetic properties of nanofluid -A critical review," Applied Thermal Engineering, vol. 28, pp. 2109-2125, 2008.

[9] R. A. Yetter, G. A. Risha, and S. F. Son, "Metal particle combustion and nanotechnology," Proceedings of the Combustion Institute, vol 32, pp. 1819-1838, 2009.

[10] D. Jackson, D. Davidson, and R. Hanson, "Application of an aerosol shock tube for the kinetic studies of n-dodecane/nano-aluminum slurries," in Proc. 44th AIAA/ASME/SAE/ASEE Joint Propulsion Conference and Exhibit, Hartford, CT, United States, 2008.

[11] H. Tyagi et al., "Increased hot-plate ignition probability for nanoparticle-laden diesel fuel," Nano Letters, vol. 8, pp. 1410-1416, 2008.

[12] E. Beloni, V. K. Hoffmann, and E. L. Dreizin, "Combustion of Decane-Based Slurries with Metallic Fuel Additives," Journal of Propulsion and Power, vol. 24, pp. 1403-1411, 2008.

[13] Y. Gan and L. Qiao, "Combustion characteristics of fuel droplets with addition of nano and micron-sized aluminum particles," Combustion and Flame, vol. 158, pp. 354-368, 2011.

[14] G. Solero, "Experimental analysis of the influence of inert nano-additives upon combustion of diesel sprays," Nanoscience and Nanotechnology, vol. 2, pp. 129-133, 2012.

[15] S. V. Patankar, "Numerical heat transfer anf fluid flow," Hemisphere Publication Corporation, Ch. 2, pp. 11-18, 1980.

[16] N. Syred, K. Kurniawana, T. Griffithsa, T. Graltona, and R. Raya, "Development of fragmentation models for solid fuel combustion and gasification as subroutines for inclusion in CFD codes," Fuel, vol. 86, pp. 2221-2231, 2007.

[17] W. A. Sirignano, "Fuel droplet vaporization and spray combustion," Progress in Energy and Combustion Science, vol. 9, pp. 291-322, 1983.

[18] S. K. Aggarwal, G. Chen, T. A. Jackson, and G. L. Switzer, "Vaporization behavior of fuel droplets in a hot air stream," International Journal of Heat and Mass Transfer, vol. 34, pp. 2669-2673, 1991.

[19] L. Nicos and W. R. Dean, "A Model of Droplet Thermodynamic and Dynamic Behaviour in the Port of a Port-Injected Engine," SAE Paper, 1996.

[20] G. M. Faeth, "Current status of droplet liquid combustion," Progress in Energy and Combustion Science, vol. 3, pp. 191-224, 1977.

[21] W. A. Sirignano, Fluid Dynamics and Transport of Droplets and Sprays, Cambridge University Press, 1999.

[22] A. Ghadimi, R. Saidur, and H. S. C. Metselaar, "A review of nanofluid stability properties and characterization in stationary conditions," International Journal of Heat and Mass Transfer, vol. 54, pp. 4051-4068, 2011
[23] Y. Xuan and W. Roetzel, "Conceptions for heat transfer correlation of nanofluids," International Journal of Heat and Mass Transfer, vol. 43, pp. 3701-3707, 2000.

[24] Y. Gan and L. Qiao, "Evaporation characteristics of fuel droplets with addition of nanoparticles under natural and forced convection," International Journal of Heat and Mass Transfer, vol. 54, pp. 4913-4922.

[25] S. R. Turns, An Introduction to Combustion: Concepts And Application, McGraw-Hill Science, 2006.

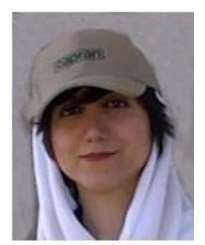

Mina Mehregan was born in Roudsar on September 21, 1984. She has obtained her bachelor's degree from Ferdowsi University of Mashhad in Mechanical Engineering in 2006. She is currently a Master student under the supervision of Prof. Mohammad Moghiman. Her research is centered on Nanopartciles application in the field of combustion and fuels.

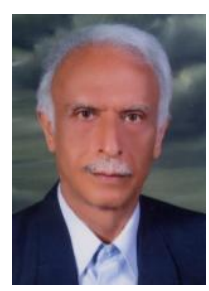

Mohammad Moghiman is a professor of mechanical engineering at Ferdowsi University of Mashhad. He was born in Nishabor on November 25, 1951. He obtained his bachelor's degree in Mechanical Engineering from University of Tehran, Iran in 1973 and then continued his academic study there until he graduated in master of Mechanical Engineering in 1975. In 1990 he earned his $\mathrm{Ph} . \mathrm{D}$. degree in Mechanical Engineering from University of Wales, United Kingdom. His major field of study was turbulent combustion flames modeling.

$\mathrm{He}$ has coauthored more than 60 publications. Three of his recent published articles are as follows: 1) M. Moghiman, and B. Aslani, "Influence of nanoparticles on reducing and enhancing evaporation mass transfer and its efficiency," International Journal of Heat and Mass Transfer, vol. 61, pp. 114-118, 2013. 2) S. M. Javadi and M. Moghiman, "Experimental study of natural gas temperature effects on the flame luminosity and NO emission," International Journal of Spray and Combustion Dynamics, vol. 4, pp. 175-184, 2012. 3) M. Vaezi, M. Passandideh Fard , M. Moghiman , and M. Charmchi, "Gasification of heavy fuel oils: A thermochemical equilibrium approach", Fuel, vol. 90, pp. 878-885, 2011. His previous research interests were in the fields of numerical modeling of Industrial processes, turbulent combustion flame simulation, pollutants emission modeling, and air conditioning. Currently he also focuses on nanotechnology applications in engineering-related systems. He has registered an invention under title of "Carbon Black Gas Furnace" in National Iranian Gas Company (NIGC).

Prof. Moghiman is a member of Iranian Society of Mechanical Engineers (ISME), and Iranian Combustion Institute (ICI). $\mathrm{He}$ was the head of Mechnaical Engineering Department of Ferdowsi University of Mashhad during the periods of 1991-1997 and 2002-2006. As well as he was the director of Graduated Studies in Ferdowsi University from 2002 till 2004. 